\title{
Characterisation of one-part geopolymer binders made from fly ash
}

\author{
Ailar Hajimohammadi ${ }^{a}$ and Jannie S. J. van Deventer ${ }^{b, c}$ \\ ${ }^{a}$ Department of Infrastructure Engineering, University of Melbourne, Victoria 3010, \\ Australia \\ ${ }^{b}$ Department of Chemical and Biomolecular Engineering, University of \\ Melbourne, Victoria 3010, Australia \\ ${ }^{c}$ Zeobond Pty Ltd, P.O. Box 23450, Docklands, Victoria 8012, Australia
}

The kinetics of one-part "just add water" geopolymerisation reaction is studied in the system of fly ash as an aluminosilicate precursor and solid sodium silicate as alkali activator. The rates of the release of $\mathrm{Si}$ and $\mathrm{Al}$ nutrients from source materials can significantly affect their availability for reaction and their extent of participation in geopolymer gel structure. The crystalline phases that usually appear in fly ash geopolymers are missing in the one-part mix binders studied here, and by increasing the $\mathrm{Si} / \mathrm{Al}$ ratio the amount of $\mathrm{Si}$ contribution in the final geopolymer gel is decreased. The sample with lower water content sees the participation of more $\mathrm{Si}$ in both stages of gel formation. Adjusting the composition of raw materials can improve the mechanical properties of the final one-part mix binder. Reasonable mechanical strength with the maximum strength of $65 \mathrm{MPa}$ is achieved.

\section{Introduction}

Concrete made by Ordinary Portland Cement (OPC) is the most common construction material, and after water, it is the most consumed material used by societies. OPC production is an energy intensive process which also releases a high amount of carbon dioxide. The cement industry is responsible for about $7 \%$ of total $\mathrm{CO}_{2}$ emissions in the world [1]. Geopolymer concrete is an alternative construction material which has the potential of significantly reducing the amount of $\mathrm{CO}_{2}$ emissions. The life cycle method has been recently used to compare the life cycle impact of geopolymers comparing to $\mathrm{OPC}[2,3]$. As a result, the $\mathrm{CO}_{2}$ emissions from geopolymer concretes can be $97 \%$ lower to up to $14 \%$ higher than standard OPC [2]. If the mix design can gain strength in ambient temperature, the resulting geopolymer has much lower impact on global warming than normal OPC [4]. 
One-part geopolymer mixtures are a newly introduced class of geopolymeric binders, developed with the aim of simplifying the difficulties in handling silicate solution-activated geopolymers. One-part geopolymers can be made by aluminosilicate precursors that are blended with solid activators [5-9], precontain high amount of alkalis [10, 11], or activated together with alkaline materials $[12,13]$. Contrary to the typical geopolymer binders in which silicate solutions are used as activators, in one-part mixtures, solid activators exist in dry mixture, and the reaction begins when water is added to the solid mix, similar to Portland cement. This technique helps to avoid using corrosive and viscous solutions for bulk production and helps with the commercial viability of geopolymer binders.

There have been some efforts in activating aluminosilicates together with alkalis at elevated temperatures to make one-part mix binders. Koloušek et al. developed one-part mix systems by calcination of kaolinite or halloysite together with powdered hydroxides [6]. The resulting strength of their samples was $1 \mathrm{MPa}$ after seven days which was weaker than usual two-part mix systems. Ke et al. made one-part mix geopolymers by calcination of red mud with sodium hydroxide at $800{ }^{\circ} \mathrm{C}$ [10]. Calcination of red mud at high temperature led to the formation of partially ordered alkaline aluminosilicate phase that gained binding properties and strength of $10 \mathrm{MPa}$ after seven days. Ye et al. also used alkali-thermal activated red mud $\left(800^{\circ} \mathrm{C}\right)$ for making one-part mix binders [11]. They added silica fume to their system to increase the strength, and they could reach $31.5 \mathrm{MPa}$ after 28 days. Feng et al. activated albite with sodium hydroxide or sodium carbonate powders at elevated temperatures (850-1150 ${ }^{\circ} \mathrm{C}$ ) [12]. Their resulting binders gained over 40MPa strength after 28 days. Peng et al. performed thermal treatment of low-quality kaolin with alkalis at $950^{\circ} \mathrm{C}$, and their binder gained over $47 \mathrm{MPa}$ strength [13]. The recent thermal treatment methods for making one-part mix binders could achieve comparable strength with two-part mix systems. However, the high temperature required for these methods limits their commercial application and increases their negative environmental impact.

Also, some efforts have been made to make one-part mix systems by blending aluminosilicates with solid activators. The researchers tried to use ambient temperature or slightly higher curing temperatures to synthesise these binders. There have been studies by Yang et al. and Yang and Song that used sodium silicate powder or combination of solid sodium silicate with sodium hydroxide to activate the pure fly ash and pure slag systems at ambient temperature [5, 14]. With the pure slag system, the resulting binder could gain 50MPa, and the pure fly ash system gained up to $9.45 \mathrm{MPa}$ strength after 28 days. Later Nematollahi et al. activated the different combination of fly ash, slag 
and hydrated lime systems using different grades of sodium silicate activators [8]. They compared the strength results of one-part mixtures with a control two-part mix sample, and they could make one-part mix formulae that achieved over $37 \mathrm{MPa}$ strength at ambient temperature. If the one-part mix is designed to gain strength at ambient temperature (or slightly higher), the resulting geopolymer will have much lower impact on global warming than normal OPC [4]. Other than the curing temperature in alkali activated mix designs, adverse environmental impacts are related to the process of alkali activators production in their life cycle analysis [3, 15]. Recently, there have been some studies that successfully used alternative alkaline activators (such rice hull ash (and/or silica fume) blended with sodium hydroxide) to reduce $\mathrm{CO}_{2}$ emissions $[15,16]$.

Most of the efforts to make one-part mix geopolymers so far were focused on making commercially and environmentally viable one-part mixes; however, there are very limited studies that explored the kinetics of geopolymer formation in these systems. The kinetics of one-part mix geopolymers made of geothermal silica as a pure silica source and sodium aluminate as the alkali and alumina source have been investigated [7], but the geopolymerisation of the pure silica system is different from the fly ash system which is usually used for making geopolymers. It is known that the time release of $\mathrm{Si}$ and $\mathrm{Al}$ species has a significant effect on the structural development of geopolymer binders $[17,18]$. The different technique of geopolymer synthesis in one-part mixtures affects the time release of the vital elements, and therefore requires a whole new concept of material design in these systems. The aim of this paper is to develop some of the established knowledge about the mechanisms of geopolymerisation to explain the reaction kinetics observed in one-part geopolymers made of fly ash.

The importance of the $\mathrm{Si} / \mathrm{Al}$ ratio and water to binder ratio, in particular, their effects on geopolymer formation and properties, has been widely discussed for two-part geopolymer mixes [19-22]. In order to study the effect of $\mathrm{Si} / \mathrm{Al}$ ratio on the formation mechanism of one-part mix fly ash geopolymers and their physical properties, one-part-mix binders are produced here from fly ash (FA) as an aluminosilicate precursor. Two $\mathrm{Si} / \mathrm{Al}$ ratios are chosen to be analysed, and the crystallinity, micro- and nanostructure of the binders are investigated. The effect of water content is also studied; one-part geopolymer mixtures are made with different $\mathrm{H}_{2} \mathrm{O} / \mathrm{Na}_{2} \mathrm{O}$ molar ratios while keeping the $\mathrm{Si} / \mathrm{Al}$ ratio constant. One-part mix products are generated successfully from $\mathrm{FA}$, and in each case a higher-strength product is generated than has been reported previously in the literature. Microstructural and nanostructural observations are able to explain the trends in strength behaviour. 


\section{Materials and methods}

The FA used in this research was sourced from Gladstone Power Station Queensland, Australia. The results of X-Ray Fluorescence (XRF) analysis of all of the materials are presented in Table 1.This FA contains $28.49 \% \mathrm{Al}_{2} \mathrm{O}_{3}$ and $47.83 \% \mathrm{SiO}_{2}$; however, a significant amount of this alumina and silica content is crystalline. It was previously calculated from a quantitative XRD analysis using SiroQuant software that only $37 \%$ of the $\mathrm{SiO}_{2}$ and $14 \%$ of the $\mathrm{Al}_{2} \mathrm{O}_{3}$ in this $\mathrm{FA}$ are $\mathrm{X}$-ray amorphous [23]. Therefore, composition calculations in this paper are based only on the amorphous fraction of FA.

Table 1. Oxide Composition of Materials As Determined by $\mathrm{XRF}^{a}$

\begin{tabular}{|l|ccccccccccccc|}
\cline { 2 - 10 } \multicolumn{1}{c|}{} & $\mathrm{SiO}_{2}$ & $\mathrm{TiO}_{2}$ & $\mathrm{Al}_{2} \mathrm{O}_{3}$ & $\mathrm{Fe}_{2} \mathrm{O}_{3}$ & $\mathrm{MnO}$ & $\mathrm{MgO}$ & $\mathrm{CaO}$ & $\mathrm{Na}_{2} \mathrm{O}$ & $\mathrm{K}_{2} \mathrm{O}$ & $\mathrm{P}_{2} \mathrm{O}_{5}$ & $\mathrm{SO}_{3}$ & $\mathrm{LOI}$ \\
\hline FA & 47.83 & 1.70 & 28.49 & 11.38 & 0.19 & 1.43 & 5.51 & 0.34 & 0.46 & 0.62 & 0.24 & 1.82 \\
\hline
\end{tabular}

$a$ Mass \%. LOI: loss on ignition at $1000{ }^{\circ} \mathrm{C}$. t: trace amounts detected.

An alternative for viscous and corrosive sodium silicate solutions should be used to assist with developing one-part mix ("just add water") geopolymers. Solid sodium silicates and sodium hydroxide are known to have the potential to slowly activate aluminosilicate materials to make geopolymer binders. In this paper, solid sodium hydroxide obtained from Aldrich with a composition of 99.9 wt. \% NaOH, and solid sodium silicate with the brand name of SS20 obtained from PQ Australia, with a composition of 75 wt. $\% \mathrm{SiO}_{2}$ and 23.3 wt. $\% \mathrm{Na}_{2} \mathrm{O}$, are used as solid activators.

To make one-part binder mixtures, FA was dry-mixed with solid sodium silicate to attain $\mathrm{Si} / \mathrm{Al}$ molar ratios of $3.6: 1$ and $4.5: 1$, then water was added to the solid mixture to attain a sample with effective $\mathrm{H}_{2} \mathrm{O} / \mathrm{Na}_{2} \mathrm{O}$ molar ratio of $12: 1,14: 1$. Sodium hydroxide was also blended with the mixtures to match the $\mathrm{Na} / \mathrm{Al}$ ratios across the sample set (the $\mathrm{Na} / \mathrm{Al}$ molar ratio was kept constant at 1.5). For all samples studied here, compositional calculations in Table 1 are based on the available silica and alumina content (i.e. using the amorphous silica and alumina content for FA) of the raw materials as determined by XRF. The samples are named according to their compositional ratios. The number outside parentheses refers to the $\mathrm{Si} / \mathrm{Al}$ molar ratio, and the number in the parentheses is the $\mathrm{H}_{2} \mathrm{O} / \mathrm{Na}_{2} \mathrm{O}$ molar ratio. Table 2 shows the mass percentage of the components in three samples studied here. 
Table 2. Mass \% of each component in the samples.

\begin{tabular}{lcccc} 
& Fly Ash & Sodium silicate & NaOH & Water \\
\hline FA 3.6(12) & 51.7 & 19.5 & 3.4 & 25.4 \\
FA 3.6(14) & 49.7 & 18.8 & 3.3 & 28.2 \\
FA 4.5(12) & 48.1 & 28.6 & 0 & 23.3 \\
\hline
\end{tabular}

The crystalline phases of the samples were studied using powder X-Ray Diffraction (XRD) collected on a Philips PW 1800 diffractometer with CuKa X-rays generated at 30mA and $40 \mathrm{kV}$ with $0.02^{\circ} 2 \theta$ steps, $2 \mathrm{~s} \mathrm{step}^{-1}$. Phase identification was carried out by comparing diffraction patterns to the ICDD PDF4 database from the International Centre for Diffraction Data, using Jade 7 software, version 5.1.2600, from Materials Data Inc.

The nonostructure of samples was analysed using the attenuated total reflectance (ATR)-FTIR method. This method allows the solid, solution and gel parts of geopolymers to be analysed simultaneously [23]. ATR-FTIR spectra were collected using a Varian FTS 7000 FT-IR spectrometer, with a Specac MKII Golden Gate single reflectance diamond ATR attachment with KRS-5 lenses and heater top plate. Absorbance spectra were collected from $4000-400 \mathrm{~cm}^{-1}$ at a resolution of $2 \mathrm{~cm}^{-1}$ and a scanning speed of $5 \mathrm{kHz}$ with 32 scans.

The microstructure of samples was examined by Scanning Electron Microscopy (SEM) using a Philips XL30 field emission gun scanning electron microscope (FEG-SEM) with an accelerating voltage of $20 \mathrm{kV}$. Fractured specimens are mounted on stubs using adhesive carbon pads and gold coated before analysis.

The mechanical strength of geopolymers was measured using an ELE ADRAuto 1500 compression testing machine, with $50 \mathrm{~mm}$ mortar cubes. Geopolymer pastes are mixed with standard quartz sand, with 2 grams of sand per gram geopolymer (calculated as solid plus solution), molded, vibrated for 10 seconds, sealed and cured in an oven at $40^{\circ} \mathrm{C}$. Samples are loaded in the testing instrument at a rate of $0.5 \mathrm{kN} / \mathrm{sec}$ until failure. Strengths reported are the average of three samples.

\section{Results and Discussion}

\subsection{Characterising crystalline phases}


Figure 1 shows the results of XRD analysis of one-part mix FA geopolymers. Crystalline phases identified are quartz ( $\mathrm{SiO}_{2}$; PDF: 00-046-1045), mullite $\left(\mathrm{Al}_{6} \mathrm{Si}_{2} \mathrm{O}_{13}\right.$; PDF: 00-015-0776), sodium metasilicate $\left(\mathrm{Na}_{2} \mathrm{SiO}_{3}\right.$; PDF: 00-016-0818), and larnite $\left(\mathrm{Ca}_{2} \mathrm{SiO}_{4}\right.$; PDF: 00-033-0302). There is also a ferrite spinel phase shown as magnetite ( $\mathrm{Fe}_{3} \mathrm{O}_{4}$; PDF: 00-019-0629).

There is no clear difference between the crystalline phases present in FA geopolymers with different $\mathrm{Si} / \mathrm{Al}$ ratios and different water contents, and the only difference is in the presence of larnite (dicalcium silicate) in the 2-day data for the FA 4.5(12) sample (Figure 1(c)), This is attributed to the presence of a small amount of larnite in the original fly ash which may mean that the as-supplied fly ash had been blended with a small amount of cement, as is sometimes observed when fly ashes are supplied for use in the concrete industry [24]. This phase hydrates during the reaction process to form amorphous phases, but appears to react more slowly in the system with a higher $\mathrm{Si} / \mathrm{Al}$ ratio.

Comparing the result of XRD analysis of one-part mix geopolymers with the literature data for traditional two-part mixtures shows that the zeolite phases that usually appear in FA geopolymers $[23,25,26]$ are missing from the one-part mix XRD results here. Faujasite or chabazite type zeolites and hydroxysodalite are known to form in two-part fly ash-sodium silicate systems with low to moderate silica contents [27-29], although crystallisation is not always observed in samples with higher silica content [25]. In the work of Yang and Song [30] on the synthesis of one-part geopolymer mixtures from fly ash activated by a combination of sodium silicate and sodium hydroxide powders, a small amount of a zeolitic phase was generated. It is not clear whether the absence of zeolites here means a lower extent of reaction in these one-part mixtures, or whether it means that all of the reactions which have happened have led to the formation of amorphous phases.

Figure 1. XRD diffractograms of a) FA 3.6(14), b) FA 3.6(12) and c) FA 4.5(12) samples as a function of curing time. Numbers refer to the age of samples in days. Q: quartz, MI: mullite, Mg: magnetite, S: sodium metasilicate, Lr: larnite. The peak marked with * is due to the aluminium sample holder

Consistent with observations in the literature, it is clear that the crystalline phases of FA are not reactive and remain mostly unchanged during the geopolymerisation process. This low reactivity of the crystalline phases of FA is the reason for considering only the amorphous fraction of this material in the composition calculations here. 


\subsection{Nanostructural analysis}

Nanostructural analysis is performed here using ex situ infrared spectroscopy. The data obtained for FA source material before reaction and one-part mix FA geopolymers with different $\mathrm{Si} / \mathrm{Al}$ ratios and different water contents are presented in Figure 2. Figure 2(a) shows the FTIR spectra of FA before reaction and the various samples after one day of reaction, and Figure 2(b) shows the variation in their main band positions over time.

The main peak at about $1050 \mathrm{~cm}^{-1}$ in FA is related to asymmetric and symmetric stretching vibrations of Si-O-Si and/or Si-O-Al bonds, the band at about $780 \mathrm{~cm}^{-1}$ is related to Al-O vibrations in $\mathrm{Al}_{2} \mathrm{O}_{3}$ structures [27, 31].

Figure 2(a) shows that the shapes of the FTIR spectra of FA geopolymers differ between the FA 3.6(12) and 4.5(12) samples, with different $\mathrm{Si} / \mathrm{Al}$ ratios, after one day of reaction, and the FA $3.6(12)$ sample has higher intensity in the peak at around $1000 \mathrm{~cm}^{-1}$. Comparing the FA 3.6(12) and FA 3.6(14) samples, with different water contents, again shows that FA 3.6(12) has higher intensity in this peak. This peak, which is located at a wavenumber between the $\mathrm{Si}-\mathrm{O}-\mathrm{Si}$ stretching vibrations of unreacted FA (close to $1050 \mathrm{~cm}^{-1}$ ) and the $\mathrm{Si}-\mathrm{O}-\mathrm{T}$ (T: $\mathrm{Si}$ or $\mathrm{Al}$ ) vibrations related to the geopolymer network (closer to $960 \mathrm{~cm}^{-1}$ ) [23], is related to nanostructural changes in the silicate network of FA that cause the main band to shift to lower wavenumbers in the early stages of reaction. As was explained by authors before [7], the formation of non-bridging oxygens due to hydrolysis-deprotonation reactions, and the contribution of $\mathrm{Al}$ to the network of forming geopolymer gels, cause changes in the distributions of lengths and angles of Si-O-T bonds in the sample, which causes the main band shift to lower wavenumbers. The higher intensity of this band in the FA 3.6(12) sample, and its presence at lower wavenumber, mean that more changes have occurred after one day in the network of this sample, which has a lower Si/Al ratio and lower water content than the other mixes analysed.

Figure 2. Ex-situ FTIR data: a) comparing FTIR spectra of FA and FA geopolymer samples after one day of reaction, and $b$ ) evolution of main Si-O-T peak positions over time

In the FA geopolymers studied here, the source of Al is fly ash, the source of alkalinity is solid sodium silicate, and the sources of $\mathrm{Si}$ are both FA particles and sodium silicate. To decrease the $\mathrm{Si} / \mathrm{Al}$ ratio of a mix design based on these precursors, it is necessary to decrease the amount of sodium silicate in the solid mixture - but then in order to keep a constant $\mathrm{Na} / \mathrm{Al}$ ratio, another 
source of $\mathrm{Na}$ is required. Sodium hydroxide was therefore mixed with the solid precursors used in the samples with lower $\mathrm{Si} / \mathrm{Al}$ ratios here. Also, the water content should be high enough to keep similar $\mathrm{H}_{2} \mathrm{O} / \mathrm{Na}_{2} \mathrm{O}$ ratios in the 3.6(12) and 4.5(12) samples which have high amounts of Na. Therefore, in order to design one-part mixtures using the solid sodium silicate source used here (with a high silica modulus; 75 wt. $\% \mathrm{SiO}_{2}$ and 23.3 wt. $\% \mathrm{Na}_{2} \mathrm{O}$, giving a modulus of 3) while keeping constant alkalinity or water content, a relatively high amount of water is required to maintain the workability of geopolymer pastes and meet the requirements of the mix design.

Figure 2(b) shows that the shift of the main band to lower wavenumbers happens most rapidly for the FA 3.6(12) sample, and that its main band shifts to $996 \mathrm{~cm}^{-1}$ in the first day of reaction compared to $1003 \mathrm{~cm}^{-1}$ for the $4.5(12)$ sample at the same time, which suggests a faster reaction rate for the FA 3.6(12) sample with a lower $\mathrm{Si} / \mathrm{Al}$ ratio. This agrees with the observation of higher intensity of the newly formed gel peak in the first day in Figure 2(a). The differences between the peak shifts in the 3.6(12) and 4.5(12) samples should not be related to differences in non-bridging oxygen sites, as the alkali contents of the systems are held constant, meaning that the differences in gel structure are instead due to the different extents of Al contribution in the gel networks of the two samples.

The peak positions at each duration of curing for the 3.6(12) sample, with its lower Si/Al ratio, are significantly higher than the peak positions of the 4.5(12) sample at similar ages. A main band at a higher wavenumber tends to indicate a higher $\mathrm{Si} / \mathrm{Al}$ ratio in the binder network. This observation, where the lower $\mathrm{Si} / \mathrm{Al}$ ratio sample appears to have a higher gel $\mathrm{Si} / \mathrm{Al}$ ratio, is unexpected and is contrary to the findings for one-part mix geothermal silica and sodium aluminate geopolymers [7], where increasing the silica content led to a higher main band wavenumber and more contribution of $\mathrm{Si}$ in the geopolymer gels.

So, Figure 2(b) suggests that upon increasing the Si/Al ratio in FA one-part mix geopolymers, the amount of Si contribution in the final geopolymer gel is decreased. This might seem improbable, but it is not impossible. The observation of slower FA dissolution (higher wavenumber after one day of reaction in Figure 2(b) and larger shoulder at $\sim 1050 \mathrm{~cm}^{-1}$ in Figure 2(a)) with increasing silicate content in these samples can be related to the relatively low concentration of small silica species in solutions with higher $\mathrm{Si} / \mathrm{Na}$ ratios, as these solutions tend to form silicate oligomers rather than containing small reactive species. Small silicate species are known to be important in geopolymerisation reactions [31-36]. At constant alkali concentration, increasing the silica concentration can lead to the formation of significant amounts of larger and more highly coordinated silicate species (containing $\mathrm{Q}^{3}$ and $\mathrm{Q}^{4}$ sites) rather than small species such as silicate 
monomers and dimers [37, 38]. Only the silanol groups found in small species are effective in promoting hydrolysis of the FA glass network [23].

There will be insufficient reactive aluminosilicate materials supplied when the extent of depolymerisation of FA is low, which will lead to less formation of geopolymer gel. The larger polymeric silicate species could potentially hinder the reaction process, or may simply remain unreacted. Therefore, the Si/Al molar ratio cannot be increased indefinitely, as has been discussed in detail for two-part geopolymer mixtures [26, 32, 33, 39], and a similar approach should be taken in the design of one-part mixtures.

Comparing the peak position graphs in Figure 2(a) for the FA 3.6(12) and FA 3.6(14) samples, with different water contents, shows that upon increasing the water content, the main band shift to lower wavenumbers is slower; the 3.6(14) sample shows a main band shift to $1005 \mathrm{~cm}^{-1}$ in one day compared to $996 \mathrm{~cm}^{-1}$ for the 3.6(12) sample. However, the sample with higher water content shifts to its lowest wavenumber after two days and then shifts back to higher wavenumbers after four days of reaction, whereas the 3.6(12) sample requires 7 days to shift back to higher wavenumbers.

As Rees et al. explained [23], the minimum position of the main band is related to the point in time when Al-rich gel is formed, and its shift back to higher wavenumbers is due to the contribution of more Si later in the reaction process, with the formation of Si-rich gel. Figure 2(b) suggests that, although changes in ash structure happen faster during the first day of reaction in the low water content sample (FA 3.6(12)), the formation of Al rich gel, followed by substitution of more Si and the formation of Si rich gel, will occur faster in the higher water content sample, FA 3.6(14).

The dissolution of FA increases with increasing $\mathrm{NaOH}$ concentration in solution. Upon increasing the water content, the alkalinity of the system is decreased, leading to less formation of nonbridging oxygens by glass hydrolysis and therefore less changes in the nanostructure of the sample in the early stages of reaction. This is why the main band shifts to a lower wavenumber after one day in the sample with lower water content.

It was also recognised before that the extent of $\mathrm{Al}$ dissolution from the fly ash particles studied here is higher than the extent of Si dissolution, and that the difference in their dissolution rates decreases over time or upon increasing the alkalinity of the system s[40]. Thus, in the FA 3.6(14) sample with high water content and lower alkalinity, the amount of $\mathrm{Al}$ in solution in the early stages of the reaction is relatively high, and consequently an Al-rich gel phase will be formed quickly in this system. However, in the 3.6(12) system, which has higher alkalinity due to its lower water content, there will be less difference between the dissolution rates of $\mathrm{Si}$ and $\mathrm{Al}$ from the ash particles, meaning that the dissolved alumina is present along with dissolved silica species from both solid 
sources (ash and sodium silicate) in the early stages of reaction, hindering the formation of the initial "Al-rich" gel.

After formation of the Al-rich gel in the 3.6(14) sample, the concentration of dissolved solids in the solution will have decreased, as they have participated in forming the gel. This increases the driving force for further dissolution of silica from the available solid sources. Now, the solid source with more undissolved Si available will be mainly the remnant FA particles, as the more reactive sodium silicate particles will have been consumed more easily in the earlier stages of reaction. So, more silica dissolves from ash particles in the later stages of the reaction; however, much less $\mathrm{Al}$ is left in the solution as most of the dissolved $\mathrm{Al}$ species have already left the solution due to gelation. Therefore, the formation of Si rich gel happens soon after dissolution of Si from ash particles in the 3.6(14) sample with high water content.

On the other hand, for the FA 3.6(12) sample with lower water content, which has dissolution of silica from both silica sources (ash particles and sodium silicate) from the early stages of the reaction, formation of the initial Al-rich gel takes more time, but as soon as formation of this gel occurs, the secondary Si-rich gel begins to form due to the presence of more dissolved silica. Therefore, as higher alkalinity affects the dissolution of silica from ash particles more than it affects the dissolution of alumina, the sample with lower water content sees the participation of more Si in both stages of gel formation, causing the peak position of the 3.6(12) system to remain slightly above the peak position in the 3.6(14) system.

As discussed earlier [17, 18], when designing solid mixtures for geopolymer precursors, the release rates of $\mathrm{Si}$ and $\mathrm{Al}$ into the solution should be considered carefully. Possibly even more so than pure compositional effects, the release rates of the gel-forming species will control nanostructure development and the final properties of the binder.

\subsection{Microstructural analysis}

Figure 3 shows SEM micrographs of one-part mix FA geopolymers after three weeks of curing. The spherical shapes of the unreacted FA particles are recognisable in these images. Comparing the microstructures of FA 3.6(12) (Figure 2(a)) and FA 3.6(14) (Figure 2(b)) shows that increasing the amount of water has negatively affected the microstructure of FA geopolymers, consistent with the FTIR findings presented above. However, comparing SEM images of FA 3.6(12) (Figure 3(a)) and FA 4.5(12) (Figure 3(c)) shows that increasing the $\mathrm{Si} / \mathrm{Al}$ ratio in a one-part mix FA geopolymer does not cause improvements in its microstructure. 
Figure 3. Scanning electron micrographs of a) FA 3.6(12), b) FA 3.6(14) and c) FA 4.5(12) samles after three weeks at $40^{\circ} \mathrm{C}$.

The $\mathrm{Si} / \mathrm{Al}$ ratios in the one-part mixtures studied here are much higher than the $\mathrm{Si} / \mathrm{Al}$ ratios of onepart GTS geopolymers studied before [7], and this can significantly affect the geopolymerisation mechanism. The as ash particles in the FA 4.5(12) sampie (Figure 3(c)) are not as tightly connected to each other with geopolymer gel as the particles in the FA 3.6(12) (Figure 3(a)) sample, and the extent of large pore formation in the sample with higher $\mathrm{Si} / \mathrm{Al}$ ratio is also higher. Also, among the three FA samples studied here, some small cracks can be observed in the SEM image of the FA 4.5(12) sample which do not exist or are too small to be observed in the other two samples.

\subsection{Mechanical strength}

Comparing the mechanical strengths of nne-part mix FA geopolymer samples (Figure 4) confirms the observations presented above regarding the nanostructure and microstructure of these samples. The higher water content sample is weaker, and there is also a marked difference between the compressive strengths of the samples with different $\mathrm{Si} / \mathrm{Al}$ ratios, where the sample with lower $\mathrm{Si} / \mathrm{Al}$ ratio has much higher strength. The FA 4.5(12) sample, which is very weak after the first week of curing, only improves its strength to about $20 \mathrm{MPa}$ after 3 weeks, which is still very low for cementitious binders. However, as it could keep its rigidity and mechanical integrity when immersed in water for 2 weeks [27], it was considered to be a successfully-formed geopolymer. The FA 3.6(12) sample also became stronger over time, with a final strength of $65 \mathrm{MPa}$ after three weeks which is a strong sample for one-part mixtures compared to the results of the studies that used similar raw materials [8, 30]. Also, comparing the strength of FA one-part mixture studied here with the strengths of two-part mix geopolymers shows that achieving $65 \mathrm{MPa}$ is very acceptable for a Gladstone fly ash geopolymer [25, 41] .

Figure 4. Strengths of one-part mix FA geopolymers as a function of curing time at $40^{\circ} \mathrm{C}$ 


\section{Conclusions}

The effects of water content and $\mathrm{Si} / \mathrm{Al}$ ratio on the reaction mechanisms and physical properties of FA one-part-mix systems have been investigated. The amounts of $\mathrm{Si}$ and $\mathrm{Al}$ nutrients provided for reaction are not always a good representation of the amounts of Si and Al that actually take part in reaction, and the rates of their release can considerably affect their availability for reaction and their extent of participation in geopolymer gel structure. Adjusting the composition of raw materials can lead to lower crystallinity, faster nanostructural changes over time, increase in $\mathrm{Si} / \mathrm{Al}$ ratio of final binder in later stages of the reaction, and denser microstructure of final binder. These changes are usually useful for improving the mechanical properties of the final one-part mix binder. In the samples studied here, the usual crystalline phases in fly ash geopolymers are missing, and by increasing the $\mathrm{Si} / \mathrm{Al}$ ratio the extent of $\mathrm{Si}$ contribution in the final geopolymer gel is decreased. Participation of more Si in both stages of gel formation is observed in the sample with lower water content. Reasonable mechanical strength with the maximum strength of $65 \mathrm{MPa}$ is achieved.

\section{Acknowledgement}

This work was funded in part by the Centre for Sustainable Resource Processing through the Geopolymer Alliance, and in part by the Australian Research Council (including partial support through the Particulate Fluids Processing Centre). The guidance and advice received from Prof John L. Provis of the University of Sheffield during the course of this research is greatly appreciated.

\section{Literature Cited}

1. Ali, M.B., R. Saidura, and M.S. Hossainb, A review on emission analysis in cement industries. Renewable and Sustainable Energy Reviews, 2011. 15(5): p. 2252-2261.

2. McLellan, B.C., R.P. Williams, J. Lay, A. van Riessen, and G.D. Corder, Costs and carbon emissions for geopolymer pastes in comparison to ordinary portland cement. Journal of Cleaner Production 2011. 19: p. 1080-1090.

3. Habert, G., J.B. d'Espinose de Lacaillerie, and N. Roussel, An environmental evaluation of geopolymer based concrete production: reviewing current research trends. Journal of Cleaner Production, 2011. 19(11): p. 1229-1238.

4. Davidovits, J. Environmental implications of Geopolymers. Materials Today 2015; Available from: http://www.materialstoday.com/polymers-softmaterials/features/environmental-implications-of-geopolymers/

5. Yang, K.H., J.K. Song, A.F. Ashour, and E.T. Lee, Properties of cementless mortars activated by sodium silicate. Construction and Building Materials, 2008. 22: p. 1981-1989. 
6. Koloušek, D., J. Brus, M. Urbanova, J. Andertova, V. Hulinsky, and J. Vorel, Preparation, structure and hydrothermal stability of alternative (sodium silicate-free) geopolymers. Journal of Materials Science, 2007. 42: p. 9267-9275.

7. Hajimohammadi, A., J.L. Provis, and J.S.J. van Deventer, One-part geopolymer mixes from geothermal silica and sodium aluminate. Industrial and Engineering Chemistry Research, 2008. 47: p. 9396-9405.

8. Nematollahi, B., J. Sanjayan, and F.U.A. Shaikh, Synthesis ofheat and ambient cured onepart geopolymer mixes with different grades of sodiumsilicate. Ceramics International 2015. 41: p. 5696-5704.

9. Abdollahnejad, Z., F. Pacheco-Torgal, J.B. Aguiar, and C. Jesus, Durability performance of fly ash based one-part geopolymer mortars. Key Engineering Materials, 2014. 634: p. 113120.

10. Ke, X., S.A. Bernal, N. Ye, J.L. Provis, and J. Yang, One-Part Geopolymers Based on Thermally Treated Red Mud/NaOH Blends. Journal of American Ceramic Society, 2015. 98(1): p. 5-11.

11. Ye, N., J. Yang, S. Liang, Y. Hu, J. Hu, B. Xiao, and Q. Huang, Synthesis and strength optimization of one-part geopolymer based on red mud. Construction and Building Materials, 2016. 111: p. 317-325.

12. Feng, D., J.L. Provis , and J.S.J. van Deventer, Thermal Activation of Albite for the Synthesis of One-Part Mix Geopolymers. Journal of American Ceramic Society, 2012. 95(2): p. 565-572.

13. Peng, M.X., Z.H. Wang, S.H. Shen, and Q.G. Xiao, Synthesis, characterization and mechanisms of one-part geopolymeric cement by calcining low-quality kaolin with alkali. Materials and Structures, 2014. 48(3): p. 699-708.

14. Yang, K.H. and J.K. Song, Workability loss and compressive strength development of cementless mortars activated by combination of sodium silicate and sodium hydroxide. Journal of Materials in Civil Engineering, 2009. 119: p. 119-127.

15. Mellado, A., C. Catalan, N. Bouzon, M.V. Borrachero, J.M. Monzo, and J. Paya, Carbon footprint of geopolymeric mortar: study of the contribution of the alkaline activating solution and assessment of an alternative route. RSC Advances, 2014. 4(45): p. 2384623852.

16. Bernal, S.A., E.D. Rodríguez, R. Mejia de Gutiérrez, J.L. Provis, and S. Delvasto, Activation of Metakaolin/Slag Blends Using Alkaline Solutions Based on Chemically Modified Silica Fume and Rice Husk Ash. Waste and Biomass Valorization, 2011. 3(1): p. 99-108.

17. Hajimohammadi, A., J.L. Provis, and J.S.J. van Deventer, Effect of Alumina Release Rate on the Mechanism of Geopolymer Gel Formation. Chemistry of Materials, 2010. 22: p. 51995208.

18. Hajimohammadi, A., J.L. Provis, and J.S.J.v. Deventer, The effect of silica availability on the mechanism of geopolymerisation. Cement and Concrete Research 2011. 41: p. 210-216.

19. Fernandez-Jimenez, A., M. Monzo, M. Vicent, A. Barba, and A. Palomo, Alkaline activation of metakaolin-fly ash mixtures: Obtain of zeoceramics and zeocements. Microporous and Mesoporous Materials, 2008. 108(1-3): p. 41-49.

20. Provis, J.L., P. Duxson, G.C. Lukey, and J.S.J. vanDeventer, Statistical Thermodynamic Model for Si/Al Ordering in Amorphous Aluminosilicates. Chemistry of Materials, 2005. 17(11): p. 2976-2986.

21. Sagoe-Crentsil, K. and L. Weng, Dissolution processes, hydrolysis and condensation reactions during geopolymer synthesis: Part II. High Si/Al ratio systems. Journal of Materials Science, 2007. 42(9): p. 3007-3014.

22. Weng, L. and K. Sagoe-Crentsil, Dissolution processes, hydrolysis and condensation reactions during geopolymer synthesis: part I - low Si/Al ratio systems. Journal of Materials Science, 2007. 42(9): p. 2997-3006. 
23. Rees, C., Mechanisms and Kinetics of Gel Formation in Geopolymers. 2007, Ph.D. Thesis, University of Melbourne.

24. Keyte, L., What's wrong with Tarong? The importance of coal fly ash glass chemistry in inorganic polymer synthesis. 2008, University of Melbourne.

25. Lloyd, R.R., The Durability of Inorganic Polymer Cements, in Chemical and Biomecular Engineering Department. 2008, University of Melbourne: Melbourne.

26. Provis, J.L. and J.S.J. van Deventer, Geopolymers: Structure, Processing, Properties and Industrial Applications. 2009, UK: Abington

27. Rees, C.A., J.L. Provis, G.C. Lukey, and J.S.J. van Deventer, Attenuated total reflectance fourier transform infrared analysis of fly ash geopolymer gel aging. Langmuir, 2007. 23: p. 8170-8179.

28. Fernández-Jiménez, A., A.G. de la Torre, A. Palomo, G. Lopez-Olmo, M.M. Alonso, and M.A.G. Aranda, Quantitative determination of phases in the alkali activation of fly ash. Part I. Potential ash reactivity. Fuel, 2006. 85(5-6): p. 625-634.

29. Provis, J.L., G.C. Lukey, and J.S.J. van Deventer, Do geopolymers actually contain nanocrystalline zeolites? A re-examination of existing results. Chemistry of Materials, 2005. 17(12): p. 3075-3085.

30. Yang, K.H., J.K. Song, K.S. Lee, and A.F. Ashour, Flow and compressive strength of alkaliactivated mortars. ACI Materials Journal, 2009. 106: p. 50-58.

31. Lee, W.K.W. and J.S.J. van Deventer, Use of infrared spectroscopy to study geopolymerization of heterogeneous amorphous aluminosilicates. Langmuir, 2003. 19(21): p. 8726-8734.

32. Criado, M., A. Fernández-Jiménez, and A. Palomo, Alkali activation of fly ash. Effect of the $\mathrm{SiO}_{2} / \mathrm{Na}_{2} \mathrm{O}$ ratio. Part I: FTIR study. Microporous and Mesoporous Materials, 2007. 106: p. 180-191.

33. Duxson, P., S.W. Mallicoat, G.C. Lukey, W.M. Kriven, and J.S.J. van Deventer, The effect of alkali and Si/Al ratio on the development of mechanical properties of metakaolin-based geopolymers. Colloids and Surfaces A: Physicochemical and Engineering Aspects, 2007. 292(1): p. 8-20.

34. Criado, M., A. Fernández-Jiménez, A. Palomo, I. Sobrados, and J. Sanz, Effect of the $\mathrm{SiO}_{2} / \mathrm{Na}_{2} \mathrm{O}$ ratio on the alkali activation of fly ash. Part II: ${ }^{29} \mathrm{Si}$ MAS-NMR Survey. Microporous and Mesoporous Materials, 2007. 109: p. 525-534.

35. Rees, C.A., J.L. Provis, G.C. Lukey, and J.S.J. van Deventer, In situ ATR-FTIR study of the early stages of fly ash geopolymer gel formation. Langmuir, 2007. 23: p. 9076-9082.

36. Provis, J.L. and J.S.J. van Deventer, Geopolymerisation kinetics. 2. Reaction kinetic modelling. Chemical Engineering Science, 2007. 62: p. 2318 - 2329.

37. Bass, J.L. and G.L. Turner, Anion distributions in sodium silicate solutions. characterization by ${ }^{29} \mathrm{Si}$ NMR and infrared spectroscopies, and vapor phase osmometry. Journal of Physical Chemistry B, 1997. 101(50): p. 10638-10644.

38. Provis, J.L., P. Duxson, G.C. Lukey, F. Separovic, W.M. Kriven, and J.S.J. van Deventer, Modelling speciation in highly concentrated alkaline silicate solutions. Industrial \& Engineering Chemistry Research, 2005. 44(23): p. 8899-8908.

39. Criado, M., A. Fernández-Jiménez, A.G. De La Torre, M.A.G. Aranda, and A. Palomo, An $X R D$ study of the effect of the $\mathrm{SiO}_{2} / \mathrm{Na}_{2} \mathrm{O}$ ratio on the alkali activation of fly ash. Cement and Concrete Research, 2007. 37: p. 671-679.

40. Hajimohammadi, A., Reaction mechanisms in solid reactant-based geopolymer systems, in Department of Chemical and Biomolecular Engineering. 2011, The University of Melbourne.

41. Provis, J.L., C.Z. Yong, P. Duxson, and J.S.J. van Deventer, Correlating mechanical and thermal properties of sodium silicate-fly ash geopolymers. Colloids and Surfaces A: Physicochemical and Engineering Aspects, 2009. 336: p. 57-63. 
Figure 1
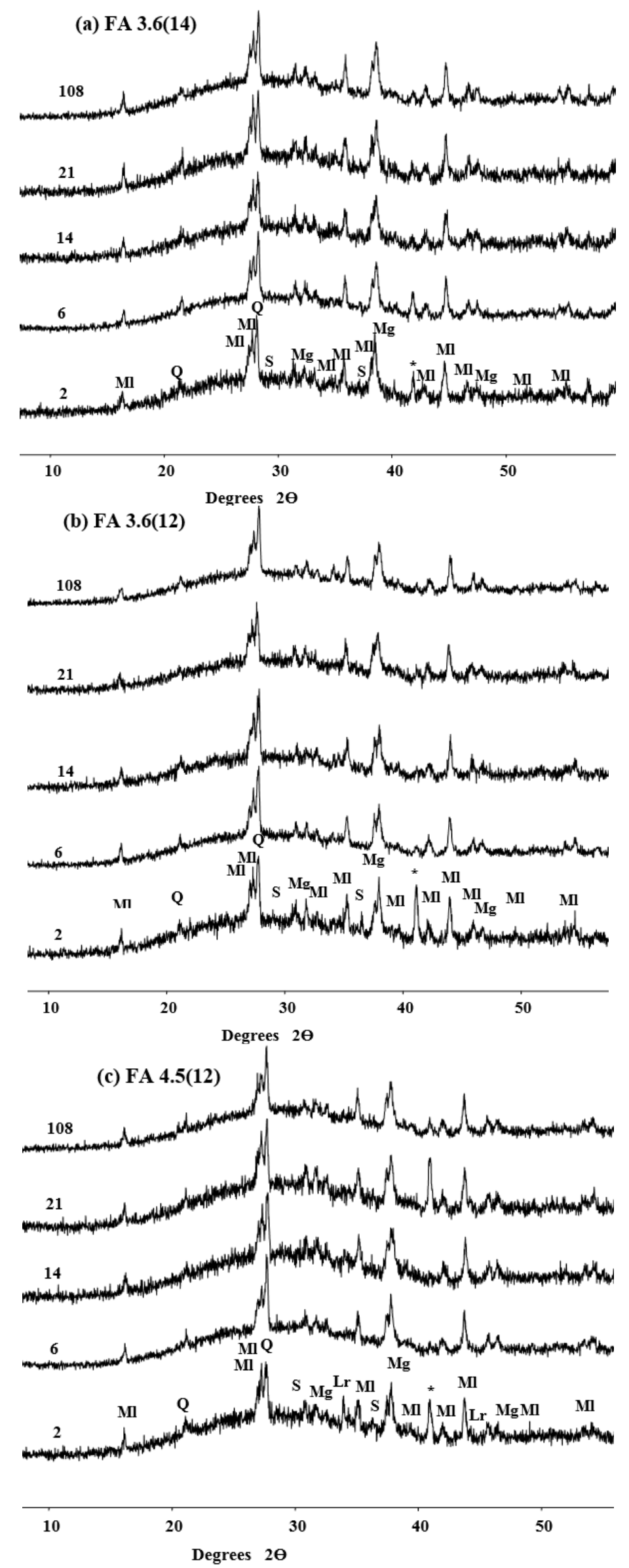
Figure 2

a)

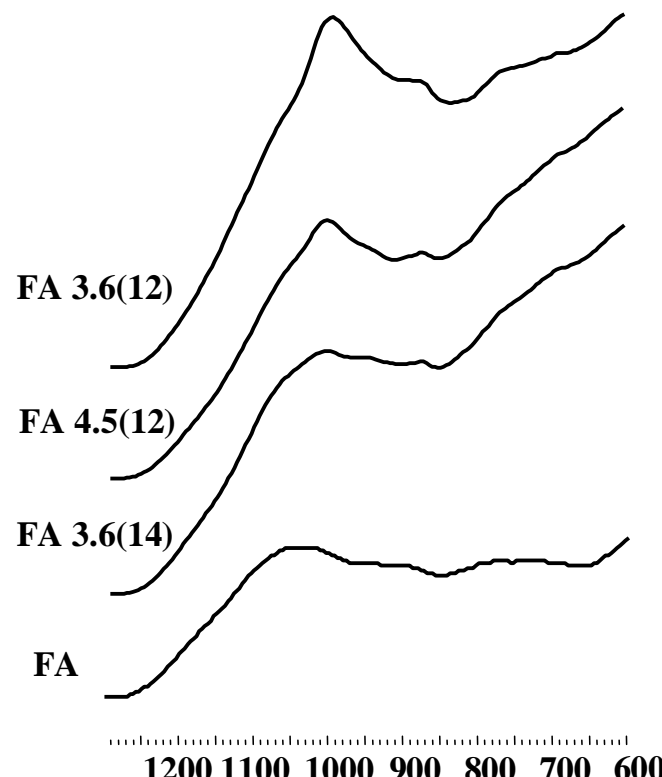

Wavenumber $\left(\mathrm{cm}^{-1}\right)$ b)

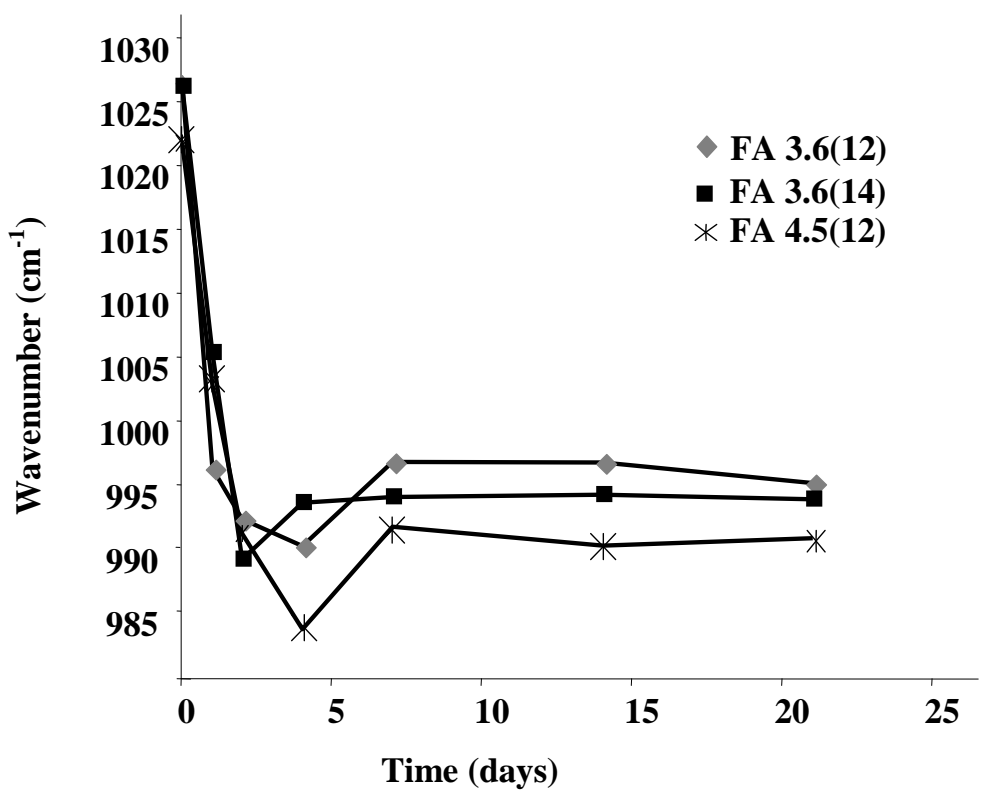

Figure 3
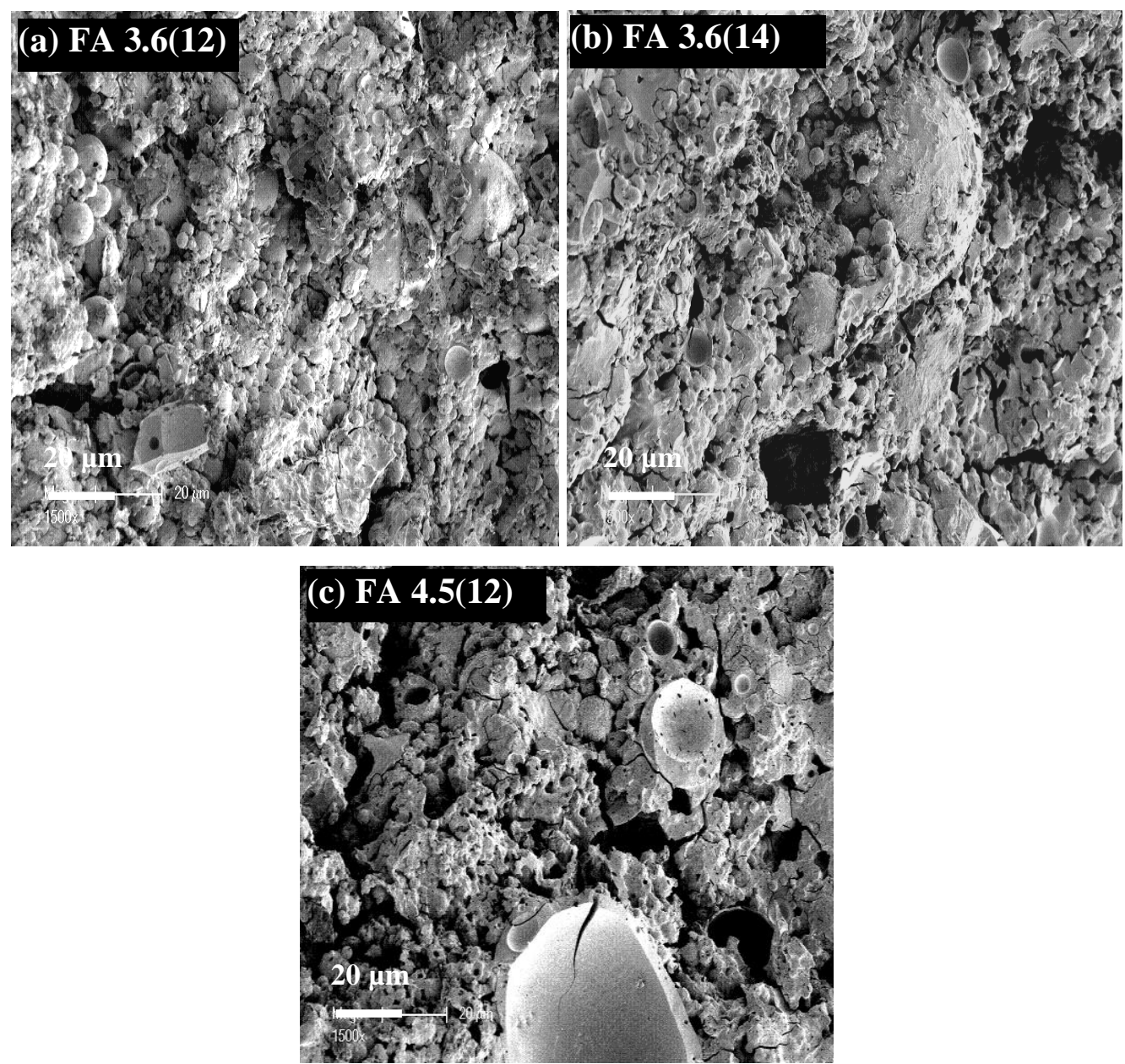
Figure 4

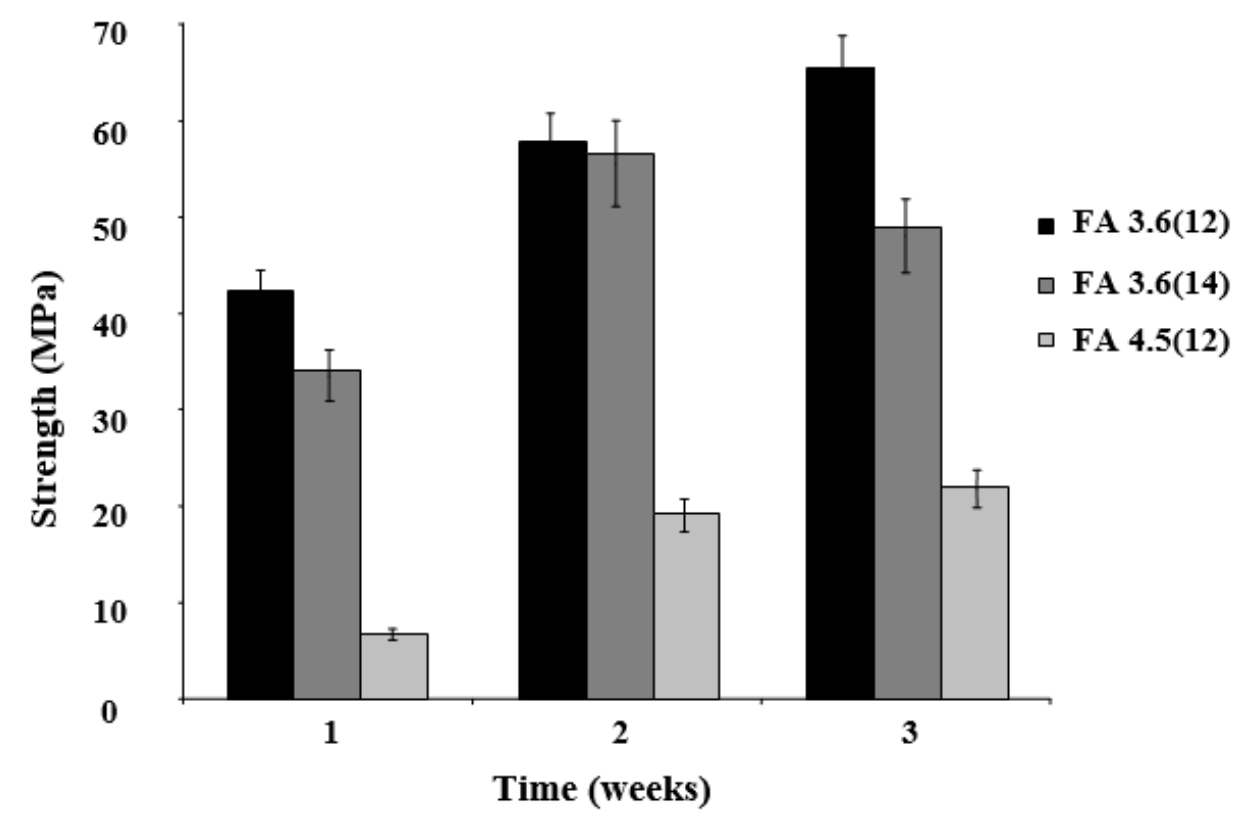




\section{University Library}

\section{- M M N E R VA A gateway to Melbourne's research publications}

Minerva Access is the Institutional Repository of The University of Melbourne

Author/s:

Hajimohammadi, A; van Deventer, JSJ

Title:

Characterisation of One-Part Geopolymer Binders Made from Fly Ash

Date:

2017-01-01

Citation:

Hajimohammadi, A. \& van Deventer, J. S. J. (2017). Characterisation of One-Part

Geopolymer Binders Made from Fly Ash. WASTE AND BIOMASS VALORIZATION, 8 (1), pp.225-233. https://doi.org/10.1007/s12649-016-9582-5.

Persistent Link:

http://hdl.handle.net/11343/283222 